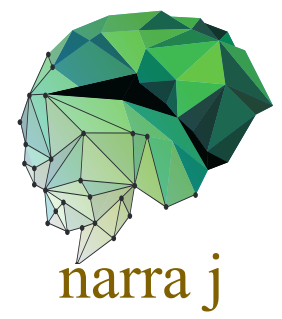

Short Communication

\title{
Correlation between depression level and headache severity: A study among medical students during the COVID-19 pandemic
}

\author{
Dika C. Bintari, ${ }^{1,2}$, Devi A. Sudibyo ${ }^{1,2^{*}}$ and Azimatul Karimah ${ }^{2,3}$ \\ ${ }^{1}$ Department of Neurology, Faculty of Medicine, Universitas Airlangga, Surabaya, Indonesia; ${ }^{2}$ Dr. Soetomo General \\ Hospital Surabaya Indonesia; ${ }^{2}$ Department of Psychiatry, Faculty of Medicine, Universitas Airlangga, Surabaya \\ Indonesia \\ *devi.as@fk.unair.ac.id
}

\section{Abstract}

Headache is the most prevailing disorder and the third leading cause of disability worldwide. The prevalence of primary headaches has been reported to increase by $2-4$ times in patients with psychiatric comorbidities, including depression. This study sought to assess the correlation between depression level and headache severity among medical students. To the best of our knowledge, this is the first study to evaluate the correlation between depression level and headache severity in Indonesia. A cross-sectional study was conducted among students of Airlangga University in 2021. To evaluate the level of depression and the severity of headache, Depression Anxiety Stress Scales (DASS-42) and Headache Impact Test 6 (HIT-6) were used, respectively. A set of validated questionnaires were used to assess students' demographic characteristics. A total of 82 medical students were included in this study and most of them were female (86.6\%). The third-semester students represented the highest proportion (45.2\%) of subjects. The mean age and body mass index (BMI) were $19.88 \pm 1.03$ and 22.55 \pm 4.44 , respectively. The average DASS-42 score was 10.98 \pm 11.47 which indicated a mild depression level. The average HIT-6 score was $45 \cdot 74 \pm 6.130$ which revealed a mild impact. The data of Spearman correlation suggested that headache severity was significantly correlated with depression level $(\mathrm{r}=0.396, \mathrm{p}<0.001)$. This study provides insights on the importance of stress management and depression prevention to decrease the risk of headache, and vice versa.

Keywords: Tension-type headache, migraine, depression, Headache Impact Test, Depression Anxiety Stress Scale

\section{Introduction}

$H$ eadache is the most common disorder and the third leading cause of disability worldwide [1, 2]. According to the International Headache Society, the global annual prevalence of primary headaches reached $46 \%$, of which, $42 \%$ are classified as tension-type headaches, $11 \%$ as migraine, and $3 \%$ as chronic headaches $[1,2]$. The prevalence rate can increase by 2-4 times in patients with psychiatric comorbidities [1,2]. Multiple factors, such as hormone levels, sleep quality, age, gender, and excessive stress leading to the development of depression, have been associated with headache severity [3-9]. Likewise, physical symptoms including headache also commonly occur in individuals suffering from depression [10]. Depression and headache are described as bidirectional since the occurrence of one disease is often followed by the other [11]. The association between depression and headache is possibly related through multiple 
mechanisms including brain development, genetic, neurotransmitter levels, environmental factors, stress, and pain modulation [11].

Depression is a serious medical condition associated with negative feelings and a decrease in quality of life $[12,13]$. The worldwide prevalence of depression reached $33 \%$ with the highest rates reported in the Middle East and South Asia [14]. Students, particularly those studying medicine, have been considerably more vulnerable to stress and had a high risk of suffering from depression [15-17]. Even prior to the coronavirus disease 2019 (COVID-19) outbreak, data on psychological stress assessment showed that stress prevalence among the students was $3 \%$ before starting studying, which increased by 2 -fold in first academic year, and reached $21 \%$ up to $56 \%$ within the final academic year $[2,15]$. During the COVID-19 pandemic, the rate of the aforementioned mental health issues has been reportedly aggravated both among general population worldwide [18] and likely among medical students. Massive changes in the education system such as that in the curricula (from offline to online class format) lead to students' concern of being separated from their community while the school process continues and preclinical and clinical practices are disrupted [19-21]. Moreover, exposure to a high-risk environment during hospital training has increasingly affected the students' psychological conditions, leading to an elevated prevalence of anxiety and depression [19-21]. This study, therefore, attempted to evaluate the correlation between depression level and headache severity among medical students during the COVID-19 pandemic in Indonesia.

\section{Methods}

\section{Study design and setting}

An online cross-sectional study was conducted among medical students of Universitas Airlangga, located in Surabaya of East Java, in August 2021. A total sampling was employed in which all medical students enrolled during the study period (i.e., Semester 3,5 and 7) were invited to participate in the study. Semester 1 students were excluded since they had not started the classes. The invitations to participate in the online survey, hosted by G-form, were distributed to all students through an official student WhatsApp communication platform. The inclusion criteria were medical students of Universitas Airlangga, participating in online class during the COVID-19 pandemic, and experiencing a primary headache. The primary headache was defined based on criteria from the International Classification of Headache Disorders (ICHD-3). Student who did not suffer from headache or those suffering from headache with focal neurological deficit, headache with head trauma, headache with brain tumor, headache with seizure, and headache with systemic disease were excluded. The students who met the inclusion criteria were enrolled after being informed of the study and signing informed consent.

\section{Assessment of depression level, headache severity, and potential confounding variable}

The questionnaire collected data on the students' characteristics (gender, age, body mass index (BMI), academic semester), type of headache, depression level, and headache severity. To ensure the type of headache, a set of validated questions were used to screen the primary headache sufferers based on criteria set by the ICHD-3 (tension-type headache and migraine).

To evaluate the level of depression, the Depression Anxiety Stress Scales (DASS-42) was used. DASS-42 consisted of 42 questions that measured three domains over the past week (depression, anxiety, and stress); each domain was measured using 14 questions [22]. In this study, only the depression domain was assessed. Each question had four possible responses and scores: "Did not apply to me at all or never (score o)"; "Applied to me to some degree, or some of the time or sometimes (score 1)"; "Applied to me to a considerable degree, or a good part of time or often (score 2)" 'and "Applied to me very much, or most of the time or almost always (score 3)". The scores ranged between o and 42 and the total scores for each participant were classified into five categories: normal (score 0-9), mild (score 10-13), moderate (score 14-20), severe (score 21-27), and extremely severe (score 28 or more) [22].

To determine the severity of headache, the Headache Impact Test (HIT-6) was utilized. HIT-6 consisted of six questions assessing headache severity and the alteration of headache 
clinical symptoms. For each question the alternative response and score were: "Never=6", "Rarely=8", "Sometimes=10", "Very often=11" and "Always=13"; therefore, the score range was 36-78. The higher the scores, the greater impact of the headache in life. The total score for each participant was classified into either no impact, mild impact, moderate impact, or severe impact as described elsewhere [23, 24].

\section{Statistical analysis}

The student t-test and Anova or the appropriate non-parametric tests were used to assess factors associated with severity of headache. To determine the correlation between students' depression level (raw score of DASS-42) and headache severity (raw score of HIT-6), the Spearman correlation coefficient was used. This analysis was used since the data did not have normal distribution based on Kolmogorov-Simonov. The analysis was performed on IBM SPSS version 22.

\section{Results}

A total of 82 out of 300 students had a primary headache and the characteristics presented in Table 1. Of the total 82 respondents, 71 (86.6\%) were female and $45.2 \%$ of the total participants were in their third semester. The mean age and BMI were 19.88 \pm 1.03 years and $22.55 \pm 4.44 \mathrm{~kg} / \mathrm{m}^{2}$, respectively. Among students with primary headache, 45.2\% (37/82) suffered from depression, and depression predominantly occurred among the third semester students (23.17\%) (Table 1). Among all participants, the mean score on the DASS-42 scale for depression domain was 10.98 \pm 11.47 (CI95\%: 8.45, 13.5), categorized as mild. Based on the severity of depression, there were almost equal number of students that suffered from mild (11\%), moderate (12.2\%), severe (11\%) and extremely severe (11\%) (Table 1). Our data suggested that migraine was the most frequent type of primary headache occurring among the respondents (69.5\%) (Table $\mathbf{1})$.

Table 1 . Baseline characteristics of the subjects with primary headache $(n=82)$

\begin{tabular}{|c|c|c|}
\hline Characteristics & & $\mathrm{n}(\%)$ \\
\hline \multicolumn{3}{|l|}{ Gender } \\
\hline & Male & $11(13.4)$ \\
\hline & Female & $71(86.6)$ \\
\hline \multicolumn{3}{|l|}{ Age (years) } \\
\hline & 18 & $6(7 \cdot 3)$ \\
\hline & 19 & $29(35.4)$ \\
\hline & 20 & $18(22.0)$ \\
\hline & 21 & $27(32.9)$ \\
\hline & 22 & $2(2.4)$ \\
\hline \multicolumn{3}{|c|}{ Body mass index (BMI) } \\
\hline & Underweight & $12(14.6)$ \\
\hline & Normal & $38(46.3)$ \\
\hline & Pre-obese & $11(13.4)$ \\
\hline & Obese level I & $17(20.7)$ \\
\hline & Obese level II & $4(4.9)$ \\
\hline \multicolumn{3}{|c|}{ Academic semester } \\
\hline & Semester 3 & $37(45.2)$ \\
\hline & Semester 5 & $19(23.2)$ \\
\hline & Semester 7 & $26(31.7)$ \\
\hline \multicolumn{3}{|c|}{ Level of depression, based on DASS-42 scale } \\
\hline & $\begin{array}{l}\text { Normal } \\
\text { Mild }\end{array}$ & $\begin{array}{l}45(54.9) \\
9(10.9)\end{array}$ \\
\hline & Moderate & $10(12.2)$ \\
\hline & Severe & $9(10.9)$ \\
\hline & Extremely severe & $9(10.9)$ \\
\hline \multicolumn{3}{|c|}{ Headache type, based on ICHD-3 } \\
\hline & $\begin{array}{l}\text { Tension-type headache } \\
\text { Migraine }\end{array}$ & $\begin{array}{l}25(30.5) \\
57(69.5)\end{array}$ \\
\hline \multicolumn{3}{|c|}{ Severity of headache, HIT- 6 scale } \\
\hline & No impact & $62(75.6)$ \\
\hline & Mild impact & $12(14.6)$ \\
\hline & Moderate impact & $4(4.9)$ \\
\hline & Severe impact & $4(4.9)$ \\
\hline
\end{tabular}


Sixty two of 82 respondents (75.6\%) that reported headaches had no impact in their life while $14.6 \%, 4.9 \%$ and $4.9 \%$ reported mild, moderate and severe impacts of headache on their life from a headache (Table 1). Of all respondents, the mean HIT-6 score was 45.74 \pm 6.13 ; CI95\%: 44.40, 47.09 (Table 2). There was an association between the level of depression and HIT-6 score $(\mathrm{p}<0.001)$; the more severe the level of depression, the higher the HIT-6 score (Table 2). The Spearman correlation suggested that severity of depression was correlated with the severity of headache $(\mathrm{r}=0.396 ; \mathrm{p}<0.001)$.

Table 2. The mean HIT-6 score and its associated factors among subjects with primary headache

\begin{tabular}{|c|c|c|c|}
\hline Characteristics & & Mean HIT-6 score & p-value \\
\hline Mean HIT-6 score & & $45.74 \pm 6.13$ & \multirow{4}{*}{0.761} \\
\hline \multirow{3}{*}{ Gender } & & & \\
\hline & Male & $46.27 \pm 7.22$ & \\
\hline & Female & $45.66 \pm 5.99$ & \\
\hline \multirow[t]{6}{*}{ Age (years) } & & & \multirow[t]{6}{*}{0.240} \\
\hline & 18 & $44.33 \pm 3.72$ & \\
\hline & 19 & $46.00 \pm 6.15$ & \\
\hline & 20 & $48.06 \pm 7.77$ & \\
\hline & 21 & $44.67 \pm 4.99$ & \\
\hline & 22 & $40.00 \pm 5.65$ & \\
\hline \multirow[t]{6}{*}{ Body mass index (BMI) } & & & \multirow[t]{6}{*}{0.145} \\
\hline & Underweight & $45.67 \pm 3.08$ & \\
\hline & Normal & $44.87 \pm 5.44$ & \\
\hline & Pre-obese & $43.55^{ \pm 5} .24$ & \\
\hline & Obese level I & $48.18 \pm 8.08$ & \\
\hline & Obese level II & $50.00 \pm 9.38$ & \\
\hline \multirow[t]{4}{*}{ Academic semester } & & & \multirow[t]{4}{*}{0.384} \\
\hline & Semester 3 & $46.68 \pm 6.43$ & \\
\hline & Semester 5 & $44.32 \pm 7.00$ & \\
\hline & Semester 7 & $45 \cdot 46 \pm 4.88$ & \\
\hline \multirow[t]{6}{*}{ Level of depression, based on DASS-42 scale } & & & \multirow[t]{6}{*}{$<0.001$} \\
\hline & Normal & $43 \cdot 49 \pm 4.78$ & \\
\hline & Mild & $49.22 \pm 4.73$ & \\
\hline & Moderate & $45.00 \pm 4.34$ & \\
\hline & Severe & $46.56 \pm 6.76$ & \\
\hline & Extremely severe & $53.56 \pm 7.24$ & \\
\hline \multirow{2}{*}{ Headache type, based on ICHD-3 } & & & \multirow[t]{2}{*}{0.221} \\
\hline & $\begin{array}{l}\text { Tension-type headache } \\
\text { Migraine }\end{array}$ & $\begin{array}{l}47.00 \pm 6.97 \\
45.19 \pm 5.70\end{array}$ & \\
\hline
\end{tabular}

\section{Discussion}

The present study was conducted to evaluate the correlation between depression level and headache severity among students of Airlangga University. The data from the Spearman correlation suggested a significant correlation between depression level and headache severity. This finding is in accordance with those reported in a previous study, suggesting that patients with depression had a greater severity and higher frequency of migraine compared to those without depression [25]. Another investigation also revealed higher scores of Visual Analogue Scale (VAS) and HIT-6 in patients with tension-type headaches and migraines compared to those without tension-type headaches or migraines [9]. In addition to depression, other variables such as BMI and smoking habits have also been reportedly associated with the severity of headache [26].

The level of serotonin, a neurotransmitter, was assumed to play a role in the occurrence of migraine. Low serotonin levels triggers the enhancement of $5 \mathrm{HT} 1 \mathrm{~A}$ receptor in the hippocampus $[27,28]$. The alteration of the receptor has been reported to be associated with the pain modulation process. Additionally, low levels of serotonin were also found in patients with depression as it plays pivotal role in mood regulation. Cortisol is a type of hormone that is involved in the stress response, and high levels of cortisol desensitization of the $5 \mathrm{HT} 1 \mathrm{~A}$ receptor $[29,30]$, leading to an increased activation of the nociceptive pathway which is related to depression events. 
Several psychosocial aspects, such as students' personality and ability to manage stress, may also contribute to the occurrence of depression. When a student is not capable of adapting to certain situations, the student will be more likely suffer from mental health problems such as anxiety and depression. Likewise, the students' personality will influence their adaptation process [31]. Nevertheless, to date, a mechanism to explain the observed association between depression and headache severity mechanisms is still not clear. Therefore, further studies are highly needed to reach a more definitive conclusion.

To the best of our knowledge, this is the first study to evaluate the correlation between depression level and headache severity in Indonesia. This study applied a cross-sectional method and online questionnaire to collect data which may bias the results. Thus, further studies using a cohort research method and direct data collection with patients are recommended.

\section{Conclusion}

The current study suggested a significant correlation between depression level and headache severity among medical students of Airlangga University. This study may provide basic information and insights on the importance of stress management and depression prevention to decrease the risk of headache occurrence, and vice versa.

\section{Ethics approval}

This study was approved by the Research Ethics Committee of Medical Faculty Universitas Airlangga, Surabaya, Indonesia (118/EC/KEPK/FKUA/2021).

\section{Acknowledgments}

We would like to thank to all participants of this study.

\section{Conflict of interest}

The authors declare no conflict of interest.

\section{Funding}

This study received no additional funding.

\section{Underlying data}

All data underlying the results are available as part of the article.

\section{How to cite}

Bintari DC, Sudibyo DA, Karimah A. Correlation between depression level and headache severity: A study among medical students during the COVID-19 pandemic. Narra J 2021; 1(3): e64. http://doi.org/10.52225/narra.v1i3.64.

\section{References}

1. Stovner L, Hagen K, Jensen R, et al. The global burden of headache: a documentation of headache prevalence and disability worldwide. Cephalalgia 2007; 27(3):193-210.

2. Steel Z, Marnane C, Iranpour C, et al. The global prevalence of common mental disorders: a systematic review and meta-analysis 1980-2013. Int J Epidemiol 2014; 43(2):476-493.

3. Szabó E, Galambos A, Kocsel N, et al. Association between migraine frequency and neural response to emotional faces: an fMRI study. Neuroimage Clin 2019; 22:101790.

4. Chai NC, Peterlin BL, Calhoun AH. Migraine and estrogen. Curr Opin Neurol 2014; 27(3):315

5. Tran DP, Spierings EL. Headache and insomnia: their relation reviewed. CRANIO ${ }^{2}$ 2013; 31(3):165-170. 
6. Panconesi A. Alcohol-induced headaches: Evidence for a central mechanism? J Neurosci Rural Pract 2016; 7(02):269275.

7. Straube A, Andreou A. Primary headaches during lifespan. J Headache Pain 2019; 20(1):1-14.

8. Adewuya AO, Ola BA, Aloba OO, et al. Depression amongst Nigerian university students. Social psychiatry and psychiatric epidemiology 2006; 41(8):674-678.

9. Song T-J, Cho S-J, Kim W-J, et al. Anxiety and depression in tension-type headache: a population-based study. PloS One 2016; 11(10):e0165316.

10. Culpepper L. Recognizing and Treating the Physical Symptoms of Depression in Primary Care. 2004.

11. Machfoed MH. Perubahan tingkat intensitas, nyeri kepala, stres psikologis, depresi kecemasan dan kadar nitrit serum, pada penderita nyeri kepala tipe tegang kronik penelitian pengukuran parameter sensitisasi sentral dari Trigeminal Nucleus Caudalis (TNC). Universitas Airlangga; 2005.

12. Richter-Levin G, Xu L. How could stress lead to major depressive disorder? IBRO Rep 2018; 4:38-43.

13. Kennedy SH. Core symptoms of major depressive disorder: relevance to diagnosis and treatment. Dialogues Clin Neurosci 2008; 10(3):271.

14. Kamble RG. Academic Stress and Depression Among College Students. 2018; 3:S107-S112.

15. Yusoff MSB, Pa MNM, Rahim AFA. Mental health of medical students before and during medical education: a prospective study. J Taibah Univ Med Sci 2013; 8(2):86-92.

16. Mousa OY, Dhamoon MS, Lander S, et al. The MD blues: under-recognized depression and anxiety in medical trainees. PloS One 2016; 11(6):e0156554.

17. Dyrbye LN, Thomas MR, Shanafelt TD. Systematic review of depression, anxiety, and other indicators of psychological distress among US and Canadian medical students. Acad Med 2006; 81(4):354-373.

18. Fahriani M, IImawan M, Fajar JK, et al. Persistence of long COVID symptoms in COVID-19 survivors worldwide and its potential pathogenesis-a systematic review and meta-analysis. Narra J 2021; 1(2).

19. Seetan K, Al-Zubi M, Rubbai Y, et al. Impact of COVID-19 on medical students' mental wellbeing in Jordan. Plos One 2021; 16(6):e0253295.

20. Halperin SJ, Henderson MN, Prenner S, et al. Prevalence of anxiety and depression among medical students during the Covid-19 pandemic: a cross-sectional study. J Med Educ Curric Dev 2021; 8:2382120521991150.

21. Alnaser AR, Joudeh RM, Zitoun OA, et al. The impact of COVID-19 pandemic on medical students' mental health and sleep quality in Jordan: a nationwide cross-sectional study. Middle East Current Psychiatry 2021; 28(1):1-10.

22. Musa R, Fadzil MA, Zain Z. Translation, validation and psychometric properties of Bahasa Malaysia version of the Depression Anxiety and Stress Scales (DASS). Asian J Psychiatr 2007; 8(2):82-89.

23. Yang M, Rendas-Baum R, Varon SF, et al. Validation of the Headache Impact Test (HIT- $6^{\mathrm{TM}}$ ) across episodic and chronic migraine. Cephalalgia 2011; 31(3):357-367.

24. Smelt AF, Assendelft WJ, Terwee CB, et al. What is a clinically relevant change on the HIT-6 questionnaire? An estimation in a primary-care population of migraine patients. Cephalalgia 2014; 34(1):29-36.

25. Chu HT, Liang CS, Lee JT, et al. Associations between depression/anxiety and headache frequency in migraineurs: a cross-sectional study. Headache: The Journal of Head and Face Pain 2018; 58(3):407-415.

26. Louter M, Wardenaar K, Veen G, et al. Allodynia is associated with a higher prevalence of depression in migraine patients. Cephalalgia 2014; 34(14):1187-1192.

27. Zhang Q, Shao A, Jiang Z, et al. The exploration of mechanisms of comorbidity between migraine and depression. J Cell Mol Med 2019; 23(7):4505-4513.

28. Papakostas GI, Chuzi SE, Sousa JL, et al. 5HT1A-mediated stimulation of cortisol release in major depression: use of non-invasive cortisol measurements to predict clinical response. Eur Arch Psychiatry Clin Neurosci 2010; 260(2):175180.

29. Cathcart S, Winefield AH, Lushington K, et al. Stress and tension-type headache mechanisms. Cephalalgia 2010; 30(10):1250-1267.

30. Peker I, Alkurt MT, Usta MG, et al. The evaluation of perceived sources of stress and stress levels among Turkish dental students. Int Dent J 2009; 59(2):103-111.

31. Liu J, Zhu Q, Fan W, et al. Online mental health survey in a medical college in China during the COVID-19 outbreak. Front Psychiatry 2020; 11:459. 